\title{
Pulmonary Embolism: A Rare Initial Manifestation of Multiple Myeloma
}

\author{
Parijat Sen ${ }^{1}$, Abhishek Kumar ${ }^{2}$, Mary Mathews $^{3, *}$, Daphne Macbruce ${ }^{4}$, Richard Miller ${ }^{4}$ \\ ${ }^{1}$ Department of Internal Medicine, St. Michael's Medical Center, Newark, USA \\ ${ }^{2}$ Department of Hematology and Oncology, St. Joseph's Regional Medical Center, New Jersey, USA \\ ${ }^{3}$ Department of Internal Medicine, St. Joseph's Regional Medical Center, New Jersey, USA \\ ${ }^{4}$ Department of Pulmonary Medicine, St. Michael’s Medical Center, Newark, USA \\ *Corresponding author: mary.mathews@live.ca
}

Received June 15, 2015; Revised June 28, 2015; Accepted July 02, 2015

\begin{abstract}
Multiple Myeloma usually presents with end organ damage like bone symptoms such as pain, pathologic fracture, renal dysfunction, chronic fatigue from anemia or symptoms of hypercalcemia. Although frequently associated with venous thromboembolisms, the presentation of multiple myeloma with pulmonary embolism as its initial manifestation is extremely rare. We report the case of a $60 \mathrm{y} / \mathrm{o}$ Hispanic male who presented with a Pulmonary Embolism, further diagnostic test revealed an underlying diagnosis of Multiple Myeloma.
\end{abstract}

Keywords: pulmonary embolism, multiple myeloma, initial manifestation

Cite This Article: Parijat Sen, Abhishek Kumar, Mary Mathews, Daphne Macbruce, and Richard Miller, "Pulmonary Embolism: A Rare Initial Manifestation of Multiple Myeloma." American Journal of Medical Case Reports, vol. 3, no. 8 (2015): 244-246. doi: 10.12691/ajmcr-3-8-6.

\section{Introduction}

Multiple Myeloma (MM) first described in 1848 is a plasma cell dyscrasia marked by replication of plasma cells with malignant potential leading to increased synthesis of monoclonal paraproteins. [1] It can affect multiple systems such as kidneys, bone, marrow etc. In younger patients who qualify, hematopoietic stem cell transplant remains the definitive therapy. [2] In other patients, the treatment options include aggressive chemotherapeutic agents such as Cyclophosphamide and Vincristine along with high dose steroids. [2] An essential drug in the treatment of MM was the immunomodulating agent Thalidomide and its congeners such as Lenalidomide which are still in use. [3] However, a landmark change came in the treatment of MM with the advent of Proteasome inhibitors such as Bortezomib and Carfilzomib which soon after replaced Thalidomide as leading choices for treating MM [4].

The association of Venous thromboembolism (VTE) and malignancies was first documented in the nineteenth century by the French physician Armand Trousseau. [5] VTE has been strongly associated with MM and Medicare data from between 1988 and 1990, including 9.389,578 patients showed an elevated incidence of VTE in Multiple Myeloma patients among other malignancies. [6] A significantly high incidence of VTE were seen to be in those patients of MM who were treated with Proteasome inhibitors or immunomodulators [7].

However, MM rarely has pulmonary embolism (PE) as its presenting manifestation. Even postmortem incidence of pulmonary embolism in myeloma patients is about $3.2 \%$. [8] Our case report highlights a rare scenario looking into the incidental rare association between MM and PE.

\section{Case Report}

A 60 year old Hispanic male, with no significant past medical history presenting with exertional dyspnea, orthopnea and dry cough for one week. He denied any calf pain, leg swelling, fevers or chills. He was a non smoker and his family history was significant only for heart disease.

On examination, he was mildly tachypneic, tachycardic and hypoxic (89\% on room air). Rest of the physical exam was positive for distended neck veins and bilateral pedal edema with clear lungs. Suspecting congestive heart failure, a bedside 2D-Echo was done which showed severe Right Ventricular Dilatation with normal left ventricular systolic function. This prompted an urgent CT Chest with Contrast which revealed extensive bilateral filling defects corresponding with bilateral pulmonary emboli (Figure 1).

He was immediately anticoagulated with low molecular weight heparin (LMWH). Subsequent labs showed anemia (Hb $8.4 \mathrm{gm} \%$ ), a total protein of $11.9 \mathrm{gm} / \mathrm{dL}$ with globulin levels of $9 \mathrm{gm} / \mathrm{dL}$. This raised the suspicion of monoclonal gammopathy. Serum Protein Electrophoresis revealed Gamma globulinemia with a M-spike of $2.4 \mathrm{gm} / \mathrm{dL}$. Further quantitative analysis showed high levels of IgG $(5912 \mathrm{mg} / \mathrm{dL})$ and low levels of IgM $(7 \mathrm{mg} / \mathrm{dL})$ and IgA $(10 \mathrm{mg} / \mathrm{dL})$ suggesting a diagnosis of plasma cell dyscrasia. 


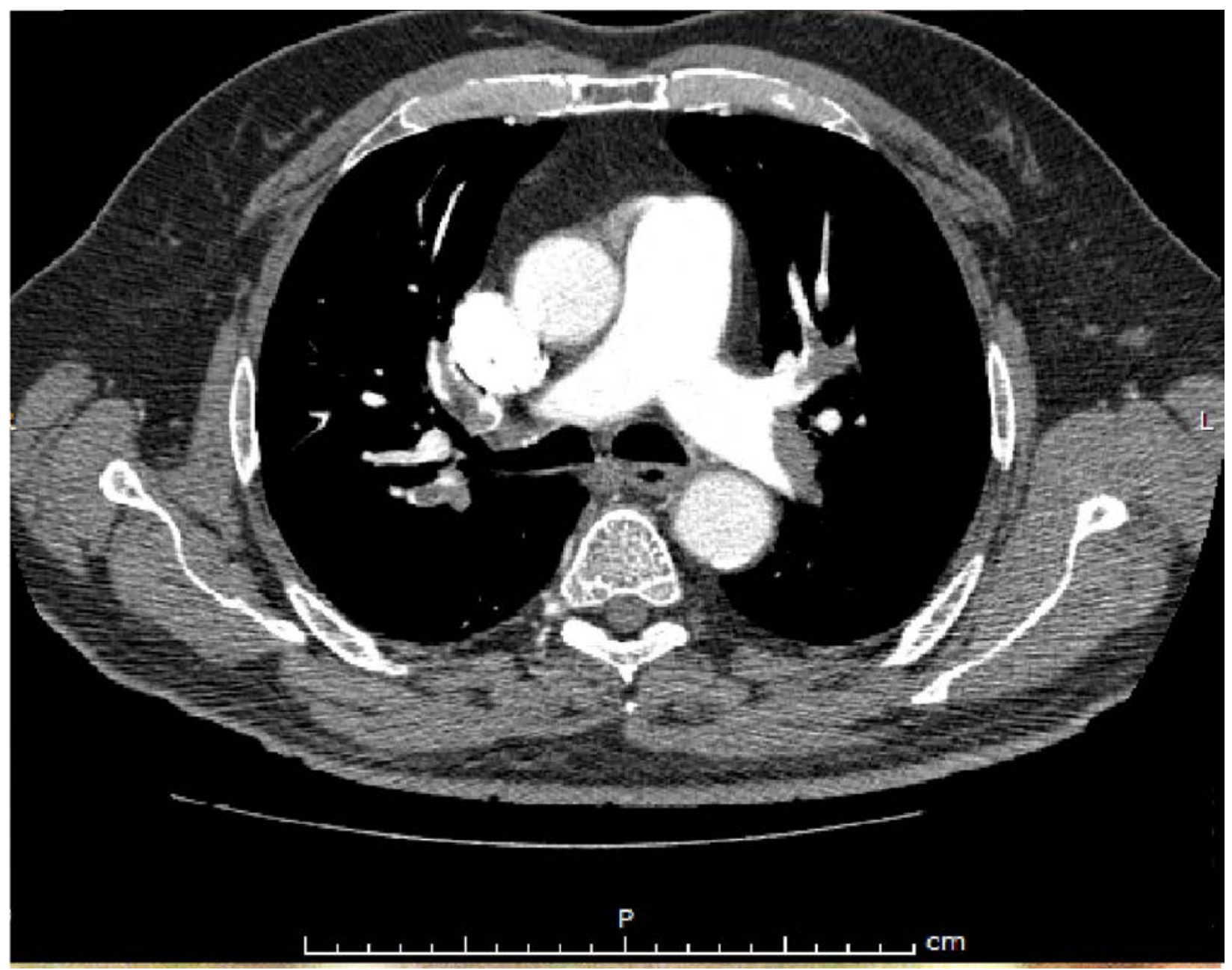

Figure 1. Extensive Bilateral Filling Defect, indicating Pulmonary Emboli

Table 1. Laboratory parameters for patient.

\begin{tabular}{|l|l|}
\hline Laboratory Parameters & Values \\
\hline Hemoglobin & $8.4 \mathrm{gm} \%$ \\
\hline Total leucocyte count & $8,000 / \mathrm{uL}$ \\
\hline Platelet count & $1,40,000 / \mathrm{uL}$ \\
\hline Brain Natriuretic Peptide Level & $842 \mathrm{pg} / \mathrm{mL}$ \\
\hline Calcium & $8.1 \mathrm{mg} / \mathrm{dL}$ \\
\hline Total protein & $11.9 \mathrm{gm} / \mathrm{dL}$ \\
\hline Albumin & $2.9 \mathrm{gm} / \mathrm{dL}$ \\
\hline Globulin level & $9.0 \mathrm{gm} / \mathrm{dL}$ \\
\hline INR & 1.2 \\
\hline
\end{tabular}

Table 2. Results of Serum and Urine Protein Electrophoresis

\begin{tabular}{|l|l|}
\hline Parameters & Values \\
\hline M- Spike & $2.4 \mathrm{gm} / \mathrm{dL}$ \\
\hline IgG Levels & $5912 \mathrm{mg} / \mathrm{dL}$ \\
\hline IgM Levels & $7 \mathrm{mg} / \mathrm{dL}$ \\
\hline IgA Levels & $10 \mathrm{mg} / \mathrm{dL}$ \\
\hline Urine Protein Level & $1500 \mathrm{mg} / \mathrm{dL}$ \\
\hline
\end{tabular}

A bone marrow biopsy showed markedly increased (43\%) Kappa light chain restricted CD38, CD138 and CD79a positive plasma cells. A FISH analysis showed CCND1/IGH translocation in 93\% of cells, confirming multiple myeloma. The patient denied any bone pain and skeletal survey was negative. His renal function and calcium levels continued to be normal.

The patient was started on Bortezomib and Dexamethasone therapy but turned out a non responder on repeat bone marrow biopsy. He refused stem cell transplant and was switched to a Lenalidomide based therapy.

\section{Discussion}

Incidence of VTE in MM is $10 \%$ with the median time to VTE diagnosis being 8.5 months from diagnosis of MM. $[9,10]$ Patho-physiological mechanisms for VTE in MM include (i) Increased levels of IL-6\& Plasminogen activator inhibitor-1 (ii) Alternation of the gel structure of fibrin; thus increasing resistance to fibrinolysis, (iii) Prothrombotic activity of paraprotein; anti-protein C, antiprotein S, lupus anticoagulant, and (iv) Acquired Activated Protein C resistance [9,10].

Treatment of multiple myeloma with Thalidomide is strongly associated with Venous Thromboembolism. [11] Thalidomide causes transient reduction in soluble Thrombomodulin levels initially. It also causes apoptosis, leading to the phosphatyl-serine induced activation of procoagulant tissue factor on cell membranes thus making these cells more thrombogenic. [12] However, it was seen that incidence of VTE in MM doesn't increase solely with Thalidomide. [13] When Thalidomide is combined with chemotherapeutic agents such as Doxorubicin or 
melphalan with prednisone, there was a sharp increase in the incidence of VTE $[14,15]$.

MM usually presents with end organ damage like bone symptoms such as pain, pathologic fracture, renal dysfunction, chronic fatigue from anemia or symptoms of hypercalcemia. Though pulmonary embolism in multiple myeloma patients on treatment is common it is rarely the initial presentation unlike solid tumors, with very few reported cases. [16] So we believe that in the right clinical setting, unprovoked VTE should raise the suspicion of plasma cell malignancies as much as solid tumors.

\section{Acknowledgements}

We acknowledge that all authors had access to the data and contributed to the manuscript.

\section{References}

[1] Kyle R.A, Rajkumar SV. Multiple Myeloma. Blood. 2008 Mar 15; 111(6): 2962-2972.

[2] Lokhorst HM, Sonneveld P, Cornelissen JJ, Joosten P, van Marwijk Kooy M, Meinema J, et al. Induction therapy with vincristine, adriamycin, dexamethasone (VAD) and intermediatedose melphalan (IDM) followed by autologous or allogeneic stem cell transplantation in newly diagnosed multiple myeloma. Bone Marrow Transplant. 1999 Feb. 23(4):317-22.

[3] Danylesko I, Beider K, Shimoni A, Nagler A. Novel Strategies for Immunotherapy in Multiple Myeloma: Previous Experience and Future Directions. Clin Dev Immunol. 2012; 2012: 753407.

[4] Richardson PG, Barlogie B, Berenson J, Singhal S, Jagannath S, Irwin D, et al. A phase 2 study of bortezomib in relapsed, refractory myeloma. N Engl J Med. 2003 Jun 26. 348(26):2609-17.

[5] Khorana AA. Malignancy, thrombosis and Trousseau: the case for an eponym. J Thromb Haemost. 2003 Dec;1(12):2463-5.

[6] Levitan $\mathrm{N}^{1}$, Dowlati A, Remick SC, Tahsildar HI, Sivinski LD, Beyth R, Rimm AA. Rates of initial and recurrent thromboembolic disease among patients with malignancy versus those withoutmalignancy. Risk analysis using Medicare claims data. Medicine (Baltimore). 1999 Sep; 78(5):285-91.

[7] Palumbo A, Palladino C. Venous and arterial thrombotic risks with thalidomide: evidence and practical guidance. Ther Adv Drug Saf. 2012 Oct; 3(5): 255-266.

[8] Sakuma M, Fukui S, Nakamura M, Takahashi T, Kitamukai O, Yazu T, et al. Cancer and pulmonary embolism: thrombotic embolism, tumor embolism, and tumor invasion into a large vein. Circ J 2006; 70:744-749.

[9] Castelli R, Ferrari B, Cortelezzi Aet al. Thromboembolic complications in malignant haematological disorders. CurrVascPharmacol 2010 Jul;8(4): 482-94.

[10] Zangari $\mathrm{M}^{1}$, Saghafifar F, Mehta P, Barlogie B, Fink L, Tricot G.The blood coagulation mechanism in multiple myeloma. Semin Thromb Hemost. 2003 Jun; 29(3):275-82.

[11] Cavo M, Zamagni E, Cellini C, et al. Deep vein thrombosis in patients with multiple myeloma receiving first-line thalidomide dexamethasone therapy. Blood 2002; 100: 2272-3.

[12] Isozumi Y, Arai R, Fujimoto K, Koyama T. Activation of Coagulation by Lenalidomide-Based Regimens for the Treatment of Multiple Myeloma. PLoS One. 2013; 8(5): e64369.

[13] Barlogie $B^{1}$, Desikan R, Eddlemon P, Spencer T, Zeldis J, Munshi $\mathrm{N}$, Badros A, Zangari M, Anaissie E, Epstein J, Shaughnessy J, Ayers D, Spoon D, Tricot G.Extended survival in advanced and refractory multiple myeloma after single-agent thalidomide: identification of prognostic factors in a phase 2 study of 169 patients. Blood. 2001 Jul 15; 98(2):492-4.

[14] Facon $\mathrm{T}^{1}$, Mary JY, Hulin C, Benboubker L, Attal M, Pegourie B, Renaud M, Harousseau JL, Guillerm G, Chaleteix C, Dib M, Voillat L, Maisonneuve H, Troncy J, Dorvaux V, Monconduit M, Martin C, Casassus P, Jaubert J, Jardel H, Doyen C, Kolb B, Anglaret B, Grosbois B, Yakoub-Agha I, Mathiot C, Avet-Loiseau H;Intergroupe Francophone du MyélomeMelphalan and prednisone plus thalidomide versus melphalan and prednisone alone or reduced-intensityautologous stem cell transplantation in elderly patients with multiple myeloma (IFM 99-06): a randomised trial. Lancet. 2007 Oct 6; 370(9594): 1209-18.

[15] Zangari $\mathrm{M}^{1}$, Siegel E, Barlogie B, Anaissie E, Saghafifar F, Fassas A, Morris C, Fink L, Tricot G.Thrombogenic activity of doxorubicin in myeloma patients receiving thalidomide: implications for therapy. Blood. 2002 Aug 15; 100(4):1168-71.

[16] Vallianou $\mathrm{N}^{1}$, Lazarou V, Tzangarakis J, Barounis R, Sioula E. Pulmonary embolism as the first manifestation of multiple myeloma. Case Rep Med. 2013; 2013: 236913. 